\title{
A INFÂNCIA (RE)CONTADA PELO FIO DA MEMÓRIA DE PSICOTERAPEUTAS SEPTUAGENÁRIOS ${ }^{1}$
}

\author{
Manoel Antônio dos Santos² \\ Universidade de São Paulo, Ribeirão Preto-SP, Brasil
}

\begin{abstract}
RESUMO. Este estudo teve por objetivo investigar os relatos de psicoterapeutas idosos sobre sua infância, buscando identificar, nas experiências de vida narradas, elementos relacionados às vivências familiares. $O$ estudo é de caráter descritivo e exploratório, de abordagem qualitativa com a utilização do método clínicoqualitativo. Participaram cinco psicoterapeutas septuagenários, escolhidos pelo critério de prestígio desfrutado junto aos pares dentro e fora de instituições psicanalíticas. Foi utilizada entrevista aberta, audiogravada e, posteriormente, transcrita na íntegra. Os relatos foram submetidos à análise de conteúdo temática. Os dados foram interpretados com base no referencial teórico psicanalítico da transmissão psíquica. $A$ análise resultou na construção de três categorias temáticas: (1) A família como rede simbólica que define a posição subjetiva de seus membros; (2) Entre a reverência e a rebeldia: a possibilidade de reinventar a tradição familiar; e (3) Construindo o pertencimento à cadeia geracional. Constatou-se que as narrativas dos psicoterapeutas sobre a infância se estruturaram em torno da vida familiar, pautada em hábitos e papéis familiares bem delimitados, com rígida divisão de funções entre pai, mãe e filhos. A posição ocupada pelo sujeito na fratria e a submissão a um mito fundador da linhagem são elementos que auxiliam na compreensão do engendramento de cada participante na cadeia intergeracional.
\end{abstract}

Palavras-chave: Psicoterapeutas; família de origem; velhice.

\section{CHILDHOOD (RE)COUNTED BY THE THREADS OF MEMORY OF SEPTUAGENARIAN PSYCHOTHERAPISTS}

\begin{abstract}
This study aimed to investigate reports of elderly psychotherapists about their childhood, seeking to identify, through the reported life experiences, elements related to family experiences. This is a descriptive and exploratory study with a qualitative approach, using the clinical-qualitative method. Five septuagenarian psychotherapists participated, chosen by the criterion of prestige recognized by peers in and outside psychoanalytic institutions. Open-ended interviews were used, which were audio-recorded and subsequently fully transcribed. The reports were processed through thematic content analysis. The data were interpreted with the support of the psychoanalytic theoretical framework of intergenerational psychic transmission. The analysis resulted in the construction of three themes: (1) The family as a symbolic network that defines the subjective position of its members; (2) Between reverence and rebellion: the opportunity to reinvent the family tradition; and (3) Building the belonging to the generational chain. It was found that the psychotherapists' narratives about childhood were structured around family life, based on habits and well-defined family roles, with a strict division of functions between father, mother and children. The subject's position in the brotherhood and submission to a founding myth of the lineage are elements that help to understand the formation of each participant in the intergenerational chain
\end{abstract}

Keywords: Psychotherapists; family of origin; old age.

\section{LA INFANCIA (RE)CONTADA POR EL HILO DE LA MEMORIA DE PSICOTERAPEUTAS SEPTUAGENARIOS}

RESUMEN. Este estudio tuvo el objetivo de investigar los relatos de psicoterapeutas ancianos sobre su infancia, buscando identificar, en las experiencias de vida narradas, elementos relacionados con experiencias familiares. Se trata de un estudio descriptivo y exploratorio, con enfoque cualitativo, utilizando el método clínico-cualitativo. Participaron

Apoio e financiamento: Conselho Nacional de Desenvolvimento Científico e Tecnológico (CNPq).

2 Endereço para correspondência: Faculdade de Filosofia, Ciências e Letras de Ribeirão Preto da Universidade de São Paulo, Departamento de Psicologia, Av. Bandeirantes, 3900, Monte Alegre, CEP 14.040-901, Ribeirão PretoSP, Brasil. E-mail: masantos@ffclrp.usp.br 
cinco psicoterapeutas septuagenarios, elegidos por el criterio de prestigio disfrutado junto a los pares dentro y fuera de instituciones psicoanalíticas. Se utilizó entrevista abierta, audio-grabada y, posteriormente, transcrita por completo. Los relatos fueron sometidos al análisis de contenido temático. Los datos fueron interpretados con base en el referencial teórico psicoanalítico de la trasmisión psíquica. El análisis resultó en la construcción de tres categorías temáticas: (1) La familia como red simbólica que define la posición subjetiva de sus miembros, (2) Entre la reverencia y rebeldía: la posibilidad de reinventar la tradición familiar; y (3) Construyendo la pertenencia a la cadena generacional. Se constató que las narrativas de los psicoterapeutas sobre la infancia se estructuraron alrededor de la vida familiar, basada en hábitos y roles familiares bien definidos, con una estricta división de funciones entre padre, madre e hijos. La posición que ocupa el sujeto en la fratría y la sumisión a un mito fundador del linaje ayudan a comprender la articulación de cada participante en la cadena intergeneracional.

Palabras-clave: Psicoterapeutas; familia de origen; vejez.

A psicoterapia vem se desenvolvendo ao longo do tempo, desde os períodos iniciais de estudo e descoberta, no início do século passado, até a contemporaneidade. Nas últimas décadas, estudos evidenciaram a efetividade dos tratamentos psicoterápicos e a psicoterapia conquistou, paulatinamente, um status e uma identidade mais consistentes (Brum et al., 2012). Evidentemente, certos requisitos são necessários para que um determinado procedimento seja reconhecido como uma intervenção psicoterapêutica profissional (Abreu, 1997). De fato, do psicoterapeuta é exigido o domínio de certas habilidades e competências de relacionamento interpessoal, além de conhecimento do referencial teóricometodológico desenvolvido em um processo de treinamento sistemático, que inclui a psicoterapia pessoal e a prática supervisionada por pares com maior experiência clínica (Santos, \& Kawakami, 2003).

Nas últimas décadas, pesquisadores dos diferentes modelos terapêuticos existentes começaram a mostrar interesse em verificar como algumas variáveis do psicoterapeuta e do paciente são responsáveis pela mudança almejada (Brum et al., 2012). Postula-se a existência de fatores específicos e não específicos que influenciam os resultados da psicoterapia. Os fatores de mudança específicos correspondem às atuações intencionais do terapeuta, ou seja, a intervenções como a interpretação, habilidade de compreensão ou correção de crenças distorcidas do paciente. Os fatores inespecíficos (ou comuns a diferentes tipos de psicoterapia) estão relacionados às qualidades inerentes a uma relação humana satisfatória, capaz de afetar positivamente o indivíduo (Hernández, 2010; Krause et al., 2006). As investigações dos fatores inespecíficos tentam determinar quais são os fatores extraterapêuticos, transversais aos diferentes tipos de psicoterapias, que resultam em mudanças.

Segundo Hernández (2010), a psicoterapia requer o desempenho de uma série de habilidades por parte do psicoterapeuta, presentes ao longo de todo o processo vivenciado com o paciente. Independentemente da postura teórica assumida, exige-se que o profissional desenvolva sua capacidade de escutar, refletir, entender, confrontar, interpretar, informar e sintetizar os conteúdos psíquicos do paciente. Considera-se que a personalidade do psicoterapeuta também seja um fator relevante (Santos, \& Kawakami, 2003).

A investigação sistemática das variáveis que influenciam o processo terapêutico pode ser uma via privilegiada para o clínico compreender tanto o êxito quanto o fracasso do tratamento (Hernández, 2010). Como vimos, as pesquisas sobre resultados da psicoterapia incluem as variáveis do psicoterapeuta como importantes vetores que influenciam a mudança (Jung, Nunes, \& Eizirik, 2007). No presente estudo são focalizadas algumas dimensões da vida pessoal do psicoterapeuta relacionadas especificamente à infância e à vida em família. Parte-se do pressuposto de que conhecer os significados atribuídos a esses aspectos relacionados ao ser cuidado e a maneira como eles foram incorporados no repertório de recursos do psicoterapeuta é um requisito fundamental para se entender 0 desenvolvimento posterior de aptidões pessoais necessárias ao exercício profissional. Em outras palavras, o modo como o psicoterapeuta significa o cuidado recebido quando criança guardaria relação com o desejo e a aptidão de cuidar psiquicamente do outro na idade adulta.

O psicoterapeuta dirige sua atenção para os aspectos da vida pessoal do paciente, buscando conhecer seus comportamentos, pensamentos, atitudes, estados emocionais e comportamentos. 
Do ponto de vista metodológico, a psicoterapia é um processo de comunicação que se dirige ao psiquismo. $O$ instrumento de comunicação é a linguagem, seja ela verbal ou não verbal (Santos, \& Kawakami, 2003). Qualquer psicoterapia tem a intenção de permitir que uma pessoa satisfaça suas necessidades de afeto e reconhecimento e de ajudá-la a corrigir atitudes, emoções e comportamentos não adaptativos que a impeçam de obter satisfações na vida.

No exercício da psicoterapia, via de regra a vida pessoal do psicoterapeuta não é colocada em questão, pois se entende que o que está em causa é a subjetividade do paciente, seu desejo inconsciente, seus conflitos emocionais e suas defesas. O profissional, ao longo de seu processo de formação, é instruído a colocar em suspenso seus impulsos, desejos e memórias, incorporando essa atitude como uma disciplina mental a ser cultivada no cotidiano da prática profissional. Isso não significa assumir uma atitude "neutra" ou distanciada. O que ocorre é que o psicoterapeuta aprende a instrumentalizar sua subjetividade para que possa exercer uma escuta qualificada do sofrimento alheio, sem borrar os limites que o separaram do outro.

Ao investigarem as percepções de psicoterapeutas e pacientes em psicoterapia psicanalítica acerca das características essenciais ao exercício da psicoterapia, Souza e Teixeira (2004) mostraram que o psicoterapeuta é reconhecido como aquele que possui condições pessoais e técnicas que envolvem disponibilidade, capacidade de escuta e estudo teórico. Nessa vertente, ser psicoterapeuta é uma construção que se dá a partir de um processo contínuo de formação, que pressupõe o desenvolvimento e apropriação de recursos psíquicos por meio da prática profissional, estudo, supervisão e tratamento pessoal.

Segundo Abreu (1997), a pessoa do psicoterapeuta compõe uma variável relevante que intermedeia mudanças independentemente de uma teoria ou técnica específica. Por essa razão, o psicoterapeuta tem merecido atenção crescente de diversas investigações (Bruns, 2011; Carvalho, \& Matos, 2011a, 2011b).

A identidade do psicanalista é definida por um conjunto de conhecimentos adquiridos ao longo do processo de formação específica e pelo desenvolvimento de diversos atributos pessoais (Souza, \& Teixeira, 2004). Esses conhecimentos são adquiridos e aperfeiçoados por meio do tratamento pessoal, da prática clínica, do engajamento em cursos teóricos e seminários clínicos, supervisões e reuniões científicas.

As qualidades necessárias para o exercício da psicoterapia podem ser desenvolvidas, segundo Souza e Teixeira (2004), desde que se tenha uma personalidade adequada, com boas condições de ego, e acima de tudo, o desejo genuíno de trabalhar com seres humanos. Ter o desejo de conhecer os fenômenos psíquicos e a dinâmica de personalidade do outro é um aspecto determinante para desenvolver as demais características, segundo o relato de psicoterapeutas analisados pelas referidas autoras. Embora existam algumas características inatas, a maioria dos atributos desejáveis pode ser desenvolvida durante o processo de construção da identidade psicoterapêutica, por meio da formação, estudo, prática, supervisão e análise pessoal. Por outro lado, entende-se que os fundamentos da personalidade do psicoterapeuta, assim como os de qualquer outro indivíduo, remontam às etapas iniciais da vida e, como tais, constituem o acervo de experiências vivenciadas particularmente na infância, no período de formação dos aspectos básicos da personalidade.

De acordo com a teoria psicanalítica, a infância é um período do desenvolvimento no qual se estruturam as bases da organização da personalidade. Os alicerces da formação do ego são assentados no período infantil, especialmente na relação de cuidados estabelecida com as figuras parentais Assim, pode-se postular que a compreensão da infância dos psicoterapeutas é uma dimensão relevante para se compreender como se organizaram os pilares de seu desenvolvimento afetivoemocional. Esse conhecimento é crucial para se entender aquilo que, na vida adulta, constituirá as características pessoais requeridas para o exercício da psicoterapia, como empatia e capacidade de se interessar pelo mundo interno do outro, fundamentais para que o paciente se sinta compreendido pelo psicoterapeuta. Esse sentimento de ser compreendido é considerado essencial, sobretudo no início do tratamento, para o estabelecimento do vínculo terapêutico (Souza, \& Teixeira, 2004).

Poucos estudos têm sido realizados a respeito da formação e atuação dos psicoterapeutas em nossa realidade, ou mesmo sobre a escolha vocacional para ingressar nessa área de atuação. Considera-se que essa escolha traduz a vinculação do profissional a uma 
determinada concepção de mundo, de homem e de vida. A literatura em psicoterapia é extremamente escassa no que concerne à investigação de aspectos como as experiências infantis $e$ as interações familiares dos psicoterapeutas. Por outro lado, reconhece-se que esses aspectos podem influenciar 0 processo de desenvolvimento de habilidades e aptidões pessoais para o exercício profissional do psicoterapeuta. Considerando essa lacuna do conhecimento, este estudo teve por objetivo investigar os relatos de psicoterapeutas idosos sobre sua infância, buscando identificar, nas experiências narradas, elementos relacionados às vivências familiares.

\section{MÉTODO}

\section{Delineamento metodológico}

O presente estudo é de caráter descritivo e exploratório e de abordagem qualitativa. Utilizouse o método clínico-qualitativo (Fontanella, Ricas, \& Turato, 2008). O enfoque clínicoqualitativo foi escolhido por ser mais apropriado ao objetivo e porque o estudo se propôs a indagar as experiências e perspectivas dos psicoterapeutas a respeito de sua infância e da família de origem.

\section{Marco teórico-conceitual}

Já se encontra bem-estabelecido na literatura que a família é matriz de relações intersubjetivas e, simultaneamente, veículo de transmissão da vida psíquica entre as gerações. Nessa concepção teórica, o contexto familiar assoma como agente de recriação das subjetividades (Magalhães, \& Féres-Carneiro, 2004 , p. 254), possibilitando o encontro de outras possibilidades, que poderão ampliar e enriquecer o acervo dos valores herdados.

Eiguer (1985) sugere que o grupo familiar tem um funcionamento inconsciente, diferente dos funcionamentos individuais isolados, o que influi na manutenção dos vínculos intrafamiliares. Com base nesse pressuposto teórico, é possível afirmar que a família cumpre uma função estruturante na organização psíquica da criança, ao permitir que ela configure sua posição subjetiva em relação aos demais membros familiares. Segundo Kaës (1997), o ser humano já nasce com a marca dessa inscrição, que the propicia o pertencimento, isto é, ser membro de um grupo - o grupo familiar. O grupo familiar, por sua vez, está inserido em outros grupos mais amplos que, por sua vez, também são direta ou indiretamente conectados à família.

Quando a herança transmitida não pode ser transformada simbolicamente, ocorre a estagnação e interrupção dos dinamismos que animam $o$ desenvolvimento $e$ as trocas intrafamiliares. Isso caracteriza a transmissão psíquica transgeracional (Kaës, 1997), condição que pode favorecer o aparecimento de sintomas e o apagamento das diferenças existentes entre as gerações.

\section{Participantes}

Participaram do estudo cinco psicoterapeutas septuagenários, oriundos de diferentes estados (dois de Pernambuco, dois de São Paulo e um do Rio Grande do Sul). Um dos participantes estava radicado havia cinco décadas na cidade de Ribeirão Preto - SP, enquanto outro havia se fixado no Rio de Janeiro desde um tempo semelhante.

Os participantes foram selecionados por indicação de profissionais que tinham pelo menos dez anos de experiência na área, os quais foram convidados a listar nomes de psicanalistas/psicoterapeutas, vinculados ou não a instituições formadoras e/ou acadêmicas, e considerados como grandes referências inspiradoras para a formação dos profissionais consultados, de acordo com a opinião desses pares. A inclusão no estudo recaiu sobre os cinco participantes mais citados. Para se chegar à lista final foram ainda levados em consideração outros critérios de inclusão: (1) ter idade igual ou superior a 65 anos - tendo em vista o objetivo de investigar psicoterapeutas idosos; (2) ter exercido atividade clínica ininterrupta desde que se graduaram; (3) encontrar-se em pleno exercício de sua atividade profissional no momento da entrevista; (4) e ter disponibilidade para participar da pesquisa. Foram excluídos os profissionais com idade abaixo de 65 anos ou com condições físicas fragilizadas.

Apenas um profissional convidado declinou do convite, alegando não poder colaborar com o estudo. O número de participantes foi definido pelo critério de saturação dos dados (Fontanella, Ricas, \& Turato, 2008).

\section{Procedimento}

As entrevistas foram agendadas por intermédio de e-mail ou telefone. Os dados 
foram coletados em local reservado, buscandose assegurar um ambiente que oferecesse conforto e privacidade, porém em situações e cenários bem diversificados: consultório particular do participante, sala do hotel no qual o participante estava hospedado em função de sua participação, como convidado, de evento científico, e sala de um edifício de escritórios, na qual o participante coordenava um grupo de estudos. Os participantes foram abordados em diferentes cidades: três em Ribeirão Preto - SP, um em Santos - SP e outro em Uberaba - MG.

Os participantes deram sua anuência ao estudo por meio da assinatura do Termo de Consentimento Livre e Esclarecido (TCLE), após receberem informações sobre a natureza e os objetivos da investigação. Para a coleta de dados foi aplicada entrevista aberta, contendo uma questão norteadora em que se solicitava do entrevistado: "Conte-me como foi a infância do senhor e como eram suas relações familiares".

Também foi elaborado um diário de campo, no qual o pesquisador anotava suas observações sobre o comportamento não verbal do participante durante a entrevista, bem como as impressões e reflexões que julgasse relevantes para o alcance do objetivo do estudo.

As entrevistas foram aplicadas individualmente, em um único encontro, cuja duração variou de 69 a 135 minutos. As conversas foram audiogravadas, mediante consentimento dos participantes, e posteriormente transcritas na íntegra.

O material coligido foi submetido à análise de conteúdo temática (Minayo, 2010). Os dados foram organizados em categorias e subcategorias, levando-se em conta a regularidade das respostas e os padrões convergentes de conteúdo dos relatos. As categorias foram determinadas a partir do consenso intersubjetivo do grupo de investigadores (Krause et al., 2006). Com base no marco teórico e no referencial metodológico e de acordo com o objetivo do estudo, foram percorridas as três etapas operacionais pertinentes à análise temática: pré-análise, exploração do material e tratamento dos resultados obtidos, com base no referencial teórico adotado. Os dados foram interpretados com o apoio do referencial teórico psicanalítico da transmissão psíquica.

Os nomes próprios utilizados no presente estudo são verdadeiros. O TCLE explicitava claramente a intenção de não se preservar o anonimato dos participantes, pois uma das metas do estudo era resgatar a história de vida de algumas das maiores personalidades vivas da área da psicoterapia no Brasil. O participante era informado de que se almejava, com este estudo, preservar parte do legado das referências nacionais pioneiras, que tanto contribuíram para sedimentar a história da psicoterapia em nosso país. Todos os psicanalistas consultados concordaram com essa condição. Com essa particularidade, o projeto foi aprovado pelo Comitê de Ética em Pesquisa da instituição universitária à qual o pesquisador está vinculado.

\section{RESULTADOS E DISCUSSÃO}

Todos os participantes eram do sexo masculino, tinham idades entre 70 e 78 anos, eram casados (três) ou separados (dois), e todos tinham filhos. Fizeram graduação em Medicina antes de optarem pela atuação como psicoterapeutas/psicanalistas. Apresentavam um percurso ininterrupto de cerca de cinco décadas de atuação em psicoterapia/psicanálise. Estavam (ou já estiveram) ativamente envolvidos no processo de formação de novos profissionais, sob a chancela de instituições formadoras ou assistenciais, trabalhando como analistas didatas ou coordenando grupos de estudo.

A análise das entrevistas resultou na construção de três categorias temáticas, que contemplaram os eixos de sustentação das narrativas sobre a infância: (1) A família como rede simbólica que define a posição subjetiva de seus membros; (2) Entre a reverência e a rebeldia: a possibilidade de reinventar a tradição familiar; (3) Construindo o pertencimento à cadeia geracional.

\section{(1) A família como rede simbólica que define a posição subjetiva de seus membros}

Os entrevistados provinham de uma constelação familiar nuclear e intacta. Em torno do núcleo familiar são tecidas histórias que valorizam a transmissão intergeracional de valores tradicionais, como o trabalho, persistência e esforço pessoal.

Os participantes narraram, com grande riqueza de detalhes, suas experiências infantis, vivenciadas junto às famílias de origem. Ao rememorarem suas trajetórias de vida, as narrativas produzidas colocam em relevo que, 
desde o princípio, eles se constituíram como sujeitos entrelaçados em uma cadeia de relações afetivas que se inscrevem em suas genealogias. Essa reconstrução autobiográfica nos ajuda a atentar para os aspectos da transmissão psíquica que se imbricam na trama familiar, desde as etapas mais precoces do ciclo vital.

David Azoubel Neto afirmou: ...a minha família era uma familia acolhedora. A gente teve assim um modelo desse acolhimento, a família toda muito aconchegante, onde você sabia... por exemplo, você tinha o seu lugar na mesa, todo mundo tinha o seu lugar na mesa, que só se sentavam naquele lugar. Se não tivesse alguém, o lugar ficava vazio, né. Mas a gente sempre sentia aquela presença. [Entrevistador: Qual que era o lugar do senhor à mesa?] O meu lugar era junto da minha mãe, à esquerda; meu pai sentava na cabeceira. Ninguém sentava, só uma mulher [filha] poderia sentar no lugar dele, os homens não sentavam, tinha toda essa coisa... [Por que razão?] Essas coisas não têm explicação, né, só mito explica essa coisa, a gente nem precisa justificar, né. Acho que, quando Freud explicou o Complexo de Édipo, muita coisa ficou explicada nesse sentido, né? Não se discutiam rituais desse tipo. Meu pai ocupava a cabeceira da mesa. Aí à esquerda dele, minha mãe sentava, e eu sentava junto dela. Os outros eram por ordem de nascimento, né. A gente chamava de "plebe rude", era do outro lado. [Posso imaginar que essa mesa era muito grande.] Era! Muito grande! Era uma mesa de mármore de uns seis metros de comprimento....

Em seu depoimento, David Azoubel Neto pinta o retrato de uma família acolhedora, calorosa e numerosa, em que todos tinham uma posição fixa, predefinida pelo papel e importância que tinham na hierarquia familiar. Assim, o lugar que ocupavam à mesa durante as refeições reproduzia as relações de poder familiar. Os critérios geração, gênero e ordem de nascimento eram definidores dos lugares a serem ocupados por cada membro da família. Esse lugar, por sua vez, guardava estreita relação com a hierarquia e o valor atribuído a cada familiar.

A família cumpre uma função estruturante da organização psíquica da criança e, nesse sentido, fornece os elementos que definem a posição subjetiva de seus membros. Segundo Kaës (2005), na trama familiar se organizam os espaços psíquicos comuns e partilhados. Como podemos identificar no excerto de fala, o fato de a família ser percebida como "muito aconchegante" está diretamente associado à possibilidade de o membro familiar saber identificar qual é o seu lugar, uma vez que "todo mundo tinha o seu lugar na mesa". Se o lugar estava desocupado, ninguém mais poderia sentar-se nele, que deveria ficar vazio para simbolizar a ausência daquela pessoa. Isto era um modo de se considerar o outro que, mesmo estando ausente, de algum modo se fazia presente ("a gente sentia aquela presença"), tendo seu lugar lembrado e velado pelos presentes.

Nos interstícios do cenário familiar se define boa parte do que somos ou do que podemos ou não podemos - ser. Como também podemos perceber pelo discurso de David Azoubel, o vínculo de filiação ancora-se na dimensão biológica, mas a transcende e se apoia em uma referência de origem materna e paterna. Kaës (2010) menciona os lugares geracionais que o sujeito ocupa, entre seus contemporâneos, novos e antigos. À medida que ele se insere em uma ordem de filiação, que é transmitida de geração a geração, ele passa a ser afetado por esses lugares geracionais, a partir dos quais ele tem a possibilidade de acesso ao segredo de sua origem e ao mistério de sua morte. Desse lugar ele também pode ter acesso à possibilidade de nomeação (ser nomeado, poder nomear) e à transmissão psíquica (ser beneficiário, poder transmitir), à função simbólica e ao pensamento a que ela permite aceder.

(2) Entre a reverência e a rebeldia: a possibilidade de reinventar a tradição familiar

Uma condição para que o sujeito possa se situar em um determinado grupo e se reconhecer como membro desse conjunto de sujeitos é que ele, tendo sido procriado, também possa ser capaz de um dia procriar, reproduzindo, assim, a unidade familiar (Kaës, 2011). Desse modo, o sujeito da filiação aflora justamente ali, no lugar ocupado por seus contemporâneos, antigos e novos. É justamente pela possibilidade de ter acesso à função simbólica e ao pensamento que o membro pode estar ausente e, mesmo assim, ser evocado com vivacidade talvez até mais intensa do que o seria se ele estivesse presente. 
Para que esse fenômeno de emergência do sujeito na cadeia familiar possa operar, é preciso um elemento a mais: o conjunto formado pelos sujeitos, que se referenciam mutuamente a partir da trama familiar, deve estar subordinado a um mito fundador da linhagem. A linhagem se articula em torno de um ancestral comum, o qual pode ser uma figura imaginária, que desempenha a função de porta-voz das necessidades do grupo. A encenação das refeições na família Azoubel não apenas comporta uma dimensão ritualística, mas também tem ressonâncias míticas. Segundo Benghozi (2005, p. 105), "o ritual assegura a transmissão do mito fundador do grupo de pertencimento".

No próximo registro de fala, percebemos certa ambivalência na relação com as manifestações de religiosidade da mãe.

David Zimerman: Mas todo o fim de semana, sábado, a minha mãe acendia duas velas, eu lembro bem, no candelabro, e fazia umas preces, algumas preces, todo final de sexta-feira. Quando o sol cai, para os judeus, já começa o sábado. Ah, essa imagem nunca me saiu da cabeça, porque eram todas as sextas, aquilo era religioso. Era regulado. [Entrevistador: $\mathrm{O}$ que acontecia?] Só uma prece a Deus para proteger todo mundo, era isso, era bem rápido. E nesses feriados religiosos, ela e as amigas dela, a gente, guri, subia lá também para dar um abraço, um beijo, é tudo uma ritualística que persiste até hoje. Eu, em certa época, eu resolvi não ir mais, para mim era importante não ir mais. O velho não entendeu isso, pensava que fosse um desaforo a ele.

A expressão "tudo uma ritualística que persiste até hoje" é carregada de crítica e envolve desaprovação para o que, na perspectiva do enunciador do discurso, é sinal de atraso, uma vez que não muda, persiste até hoje. No excerto acima podemos notar a função agregadora do ritual e o exercício de reafirmação dos lugares e posições assumidos por pais e filhos, incluindo as obrigações que cabiam aos últimos, no sentido de respeitar a regularidade da celebração. O problema surge quando o filho decide romper com sua parte na "ritualística", provocando imediata reação do pai, que teme a possibilidade de quebra do pacto que assegura a transmissão do mito (catálogo de crenças compartilhadas) fundador do grupo de pertencimento (judaico, no caso).

A família é porta-voz de um imperativo que articula determinado regime desejante, que situa o sujeito e, ao mesmo tempo, o perpetua em um lugar (Rosa, 2003). Esse lugar adjudicado a cada membro muitas vezes se perpetua por meio de mitos, que são como arquivos vivos, nos quais os elementos estão dispostos de determinada maneira. Quando há dificuldades graves que obstruem 0 desenvolvimento emocional, podemos estar diante de uma "marca" da reconstrução de gerações passadas, algo que ficou marcado a ferro e fogo, e que, ao se transmitir transgeracionalmente, esboça-se nos herdeiros dos enredos familiares por repetição. O conteúdo exato dessa repetição foi claramente enunciado na expressão declinada por David Zimerman: "Essa obsessividade o velho passou para mim, eu passei para os meus filhos, que estão passando para os filhos deles." Vejamos, em aproximação mais focalizada, em que contexto esse enunciado aflorou no discurso do entrevistado.

[Entrevistador: O senhor acha que, a partir dessa situação que se formou lá aos 13 anos com seu pai, mudou algo na relação de vocês?] David Zimerman: ...era boa. Eu me lembro que esse irmão que saiu de casa, o velho surrava porque ele não entendia, pensava que ele queria vagabundear. Me lembro de uma irmã que ele combinou que ela voltaria às dez horas para casa e ela voltou à meia-noite, estava com as amigas lá em um baileco, me lembro que apanhou; mas na época era comum, não era nem... [evita pronunciar a palavra: abuso]. E eu não apanhei nenhuma vez, de apanhar não, nenhuma vez. Por esses dias eu estava falando com um irmão meu, o caçula; ele também nunca apanhou, então temos uma imagem predominantemente boa, porque ele era muito sério. Sabe, na época do fio de bigode, se você dizia uma coisa... mesmo depois se dando conta que era um mau negócio, que ele ia perder muito, cumpria! Isso passou para nós, se está falando com o meu filho, com os que são filhos dele... e foi passando, ele [o filho] é a mesma coisa, obsessivo....

Nesse excerto de fala nota-se a maneira severa de o pai punir o comportamento desviante do filho ou a indisciplina da filha, 
naquela "época do fio de bigode". Houve cenas recorrentes de abuso físico contra os irmãos, que o entrevistado tenta justificar ao afirmar que naquela época isso não era visto como abuso infantil. A conduta paterna é naturalizada como um modo aceitável de coibir a transgressão dos adolescentes rebeldes. Há uma tentativa evidente de poupar a imagem do pai, restaurando sua autoridade e a credibilidade da competência paterna. Evoquemos neste momento o que diz Benghozi (2005, p. 106) a propósito do que ele chama de "ritualização do perdão": "... a empatia com o humano parece ser a melhor prevenção para tratar a ferida da humilhação". Outro aspecto que reverbera na fala de Zimerman é a transmissão de traços de caráter, como a obsessividade, reconhecida como elemento que circula recorrentemente na relação entre pais e filhos.

\section{(3) Construindo o pertencimento à cadeia geracional}

Por vezes, a peculiaridade da posição assumida pelo sujeito na trama familiar (por exemplo, devido à ordem e às circunstâncias do nascimento) representa o fator mais decisivo para delimiar a configuração familiar e proporcionar coesão ao grupo:

Orestes Forlenza Neto: Minha família era muito parecida com a do Winnicott. Eu era o temporão, 12 anos mais velho [dáse conta do lapso que cometera e corrige a informação: "mais novo"], mais novo que a minha irmã mais velha, e nove anos mais novo que a segunda. Elas me queriam bem, mas a minha irmã mais velha me adotou, ela me adotou nitidamente e era ela quem me paparicava. Era uma figura excelente, minha irmã. A gente via que ela gostava muito de mim, que eu era parte da vida dela, não tanto das preocupações como a minha mãe tinha, mas muito mais da... com a... ela ficava, vamos dizer, com a parte de brincar, né. Um dia eu fiquei com uma crise de... eu era pequenininho, de colo, eu não sei como eu lembro dessa imagem... E eu chorava e ela tentava me distrair, e ela me distraía muito, muito. Essa imagem que eu gravei assim. [Pausa] Então eu acho que foi isso, eu me sentia amado, bastante amado.

O fato de ter sido filho "temporão" fez com que Orestes fosse "adotado" pela irmã mais velha, com uma vantagem adicional, percebida ao ser cuidado: ela era "afetiva" sem ser tão "angustiada" como a mãe. Essa irmã o entretinha com atividades lúdicas e também era quem lhe dava "colo" (holding) nos momentos de sofrimento. A imagem gravada na mente de Orestes é a da irmã cuidadora, consistentemente disponível e acolhedora, que alivia sua dor e o envolve em sua afetividade, em uma atitude zelosa e protetora.

Ainda no que concerne à vida familiar, Orestes conta que a primeira lembrança que tem registrada na memória foi o "momento em que eu estava no colo da minha irmã chorando, com meus pais por perto". Ele se recorda de ter cerca de um ano e meio na época. Essa narrativa é sustentada sem qualquer indício de dúvida quanto à possível veracidade ou possibilidade de ter acesso a registros mnemônicos de uma fase tão precoce da vida. O convívio familiar durante a primeira infância foi descrito por ele como "muito bom, muito bom".

\begin{abstract}
Orestes: Meu pai tinha uma padaria e minha mãe ajudava nessa situação, ela costurava também, mas ajudava. [pausa] E no nível de classe média da família da minha mãe, ela provavelmente era a pessoa que tinha o nível socioeconômico mais baixo do que as irmãs, os irmãos e coisa e tal, e isso causava sofrimento para ela.... Mas, quando ela, finalmente... [muda abruptamente o fluxo da conversa] Será que eu estava fazendo psicanálise já nessa idade? [riso].
\end{abstract}

$\mathrm{Na}$ fala de Orestes vemos como a família se organiza a partir das novelas familiares, articuladas nos núcleos de origem de cada um dos cônjuges. Com o nascimento dos filhos, uma nova serialidade é inscrita. Kaës (2010) mostra que a filiação está intimamente associada à existência de pelo menos três gerações sucessivas, unidas por um denominador comum que lhes serve de referência. Esse ponto comum entre as gerações é um mito de origem. É por referência a esse mito compartilhado que alguém pode se situar em um dado grupo de sujeitos e se reconhecer como membro desse grupo. Vejamos como isso se articula na fala de outro participante - Júlio de Melo Filho:

[Entrevistador: Hoje você se considera um cidadão carioca?] Júlio: Eu me considero um cidadão pernambucano 
que mora no Rio. Eu tenho muita raiz em Pernambuco. [Que tipo de raiz?] Tenho família lá, a maioria da minha família mora lá, eu tenho muita raiz na música pernambucana, na cultura pernambucana, entendeu?

Em termos de transmissão psíquica intergeracional, a permanência do legado transmitido pela via paterna está nitidamente delineada no seguinte relato:

David Zimerman: ... mas tem dois tipos
de obsessivo: tem o obsessivo demais,
que fica uma camisa de força: "não
posso fazer isso, não posso fazer
aquilo", no caso, ficou o lado bom da
obsessividade em todos nós: o velho, eu
estava dizendo, passou para mim, eu
passei para os meus filhos, que estão
passando para os filhos deles, quem
sabe um pouco demais, mas está bom.
[Entrevistador: E o outro lado da
obsessividade?] Não tivemos nenhuma
psicopatia, não tivemos na familia até
hoje. Temos algumas separações, que
nem isso tinha, mas assim, que possa
envergonhar ou preocupar a gente, não,
até o momento. [E o lado bom da
obsessividade, qual é?] O lado bom
porque tu ficas sério, dedicado às coisas
que tu fazes, com ordem, com método,
com disciplina, mas principalmente a
consideração pelo outro fica. Então fica
um obsessivo nos detalhes do que tu
queres fazer, porque tem um superego
te dizendo: "lsso não está certo"; então
se fica em dose adequada tu te torna
uma pessoa confiável, que os demais
acreditam-te, então, tu já vai... nesse
sentido, é bom. Para mim é o melhor
traço de caráter que tem, se não for
demais.

Essa fala é ilustrativa de como a família pode funcionar como espaço de transmissão de traços de caráter que, na avaliação daquele que agora ocupa um papel de transmissor, podem ser úteis para suprir as necessidades de adaptação ao mundo, instrumentalizando aqueles que os recebem a se tornam competentes para enfrentar os problemas da vida.

No próximo depoimento, a ordem de nascimento emerge nitidamente como marca discursiva: di Loreto conta que o fato de ser o filho caçula de uma prole numerosa foi decisivo nas expectativas familiares de que ele se tornasse padre ou médico.

\begin{abstract}
di Loreto: Como eu sou o oitavo e último filho de uma familia de imigrantes italianos, é compreensível que eles desejavam ter um filho médico... Aí dividia: uma parte da familia queria ter um filho padre e a outra queria um filho doutor. Todos os meus irmãos se negaram a estudar, quiseram se independizar logo, ganhar a vida logo e pararam todos a escola no nível do ginásio. E eu era a última esperança, então eu fui muito pressionado pra me tornar ou padre ou médico. Como a primeira escolha é assim... terrível, eu acabei indo para a medicina.
\end{abstract}

Curiosamente, di Loreto não utiliza a palavra filho ou irmão "caçula" para referir-se a si mesmo, mas afirma ter sido "o oitavo e último filho". Essa posição na fratria contrasta com outras trajetórias pessoais/familiares, como as de David Azoubel e Julio de Mello Filho, que ocupavam o lugar de primogênito e viveram as injunções familiares próprias dessa condição. Ocorre que, como os irmãos de di Loreto não completaram a educação formal, ele "era a última esperança" dos pais. Daí ter enfatizado que era o oitavo e último filho, situação na qual o acento é colocado não tanto na posição ocupada na serialidade familiar, mas no fato de ser "o último", "o que restava", o que deveria, portanto, corresponder à expectativa parental.

Havia, aparentemente, um lugar bem específico que the era reservado no desejo dos pais. Essa expectativa não era traduzida apenas em sinais indeléveis, mas em atitudes explícitas dos pais, que ele denomina de "pressão": ele diz, textualmente, ter sido "muito pressionado" para se tornar padre ou médico. Entre a cruz e o esculápio, o que escolher? Esse dilema sustentava o anseio de pertencimento à família. Segundo Eiguer (1985), os filhos, ao nascerem, já vêm ao mundo com expectativas depositadas pelos pais e conteúdos provenientes de outras gerações. É tentador pensarmos a posterior escolha do ofício de psicoterapeuta, que se deu (como em todos os participantes) logo após ter concluído a faculdade de medicina, pela via da psiquiatria ("eu entrei pela psiquiatria"). A escolha da carreira pode ser entendida como uma espécie de formação de compromisso (não necessariamente de ordem sintomática) entre as duas expectativas parentais, pois, ao escolher cursar medicina, di Loreto cedeu ao desejo de uma das facções da família, mas ao seguir a carreira de psicoterapeuta/aconselhador, ele bem pode ter atendido inconscientemente à outra convocação familiar, pois, no imaginário 
coletivo, a figura do sacerdote está muito associada à vocação de escutar e ajudar o outro.

\section{CONSIDERAÇÕES FINAIS}

Neste estudo, as narrativas biográficas da infância se estruturaram em torno da vida familiar, pautada em hábitos e papéis familiares bem delimitados, com rígida divisão de papéis entre pai, mãe e filhos. Esse achado é consistente com as características da família brasileira da primeira metade do século passado, época em que os psicoterapeutas viveram sua infância.

Os dados sugerem que, na resolução que cada herdeiro oferece ao legado recebido na dinâmica intergeracional, conciliam-se movimentos conservadores e transformadores. Parte da herança psíquica é endossada e reproduzida na relação com os descendentes, enquanto outra parte é criativamente reinventada pelo confronto (mas não ruptura) com a tradição paterna. Desse modo, os participantes se situam, no contínuo da cadeia geracional, como elos que operam a transição entre demandas de continuidade e transformação do legado familiar. Entre os meandros da filiação e da afiliação, parte do material psíquico transmitido é submetida à reelaboração do romance familiar (Kaës, 2010).

Para que se possa adquirir maior conhecimento científico válido acerca da psicoterapia e seus efeitos, é preciso ampliar o conhecimento que se tem a respeito dos contextos humanos em que a psicoterapia se desenrola (Krause, 2011). A pessoa do psicoterapeuta é parte desse contexto humano em que a psicoterapia acontece, por isso a vivência da infância do psicoterapeuta é uma dimensão basilar para se compreender o percurso de constituição de sua subjetividade, que é parte inseparável de sua atuação profissional, na medida em que constitui seu ser-psicoterapeuta.

\section{REFERÊNCIAS}

Abreu, J. R. P. (1997). Psicoterapeutas no Brasil: formação e atividades terapêuticas - estudo piloto. Arquivos Brasileiros de Psicoterapia Psicanalítica, 4(1), 45-60.

Benghozi, P. (2005). Resiliência familiar e conjugal numa perspectiva psicanalítica dos laços. Psicologia Clínica, 17(2), 101-109.

Brum, E. H. M., Frizzo, G. B., Gomes, A. G., Silva, M. R., Souza, D. D., \& Piccinini, C. A. (2012). Evolução dos modelos de pesquisa em psicoterapia. Estudos de Psicologia (Campinas), 29(2), 259-269.
Bruns, M. A. T. (2011). Psicoterapeutas iniciantes: os desafios das diversidades afetivo-sexuais. Arquivos Brasileiros de Psicologia, 63(1), 64-74.

Carvalho, H. M., \& Matos, P. M. (2011a). Ser e tornar-se psicoterapeuta parte I: diálogo entre experiências pessoais e profissionais. Psicologia: Ciência e Profissão, 31(1), 8095.

Carvalho, H. M., \& Matos, P. M. (2011b). Ser e tornar-se psicoterapeuta parte II: diálogo entre mudanças pessoais e profissionais. Psicologia: Ciência e Profissão, 31(4), 778799.

Eiguer, A. (1985). Um divã para a família (Leda M. V. Fischer, Trad.). Porto Alegre: Artes Médicas.

Fontanella, B. J. B., Ricas, J., \& Turato, E. R. (2008). Amostragem por saturação em pesquisas qualitativas em saúde: contribuições teóricas. Cadernos de Saúde Pública, 24(1), 17-27.

Hernández, E. L. (2010). El escuchar como elemento esencial em la psicoterapia. Psychologia: Avances de la Disciplina, 4(1), 133-134.

Jung, S. I., Nunes, M. L. T., \& Eizirik, C. L. (2007). Avaliação de resultados da psicoterapia psicanalítica. Revista de Psiquiatria do Rio Grande do Sul, 29(2), 184-196.

Kaës, R. (1997). O grupo e o sujeito do grupo: Elementos para uma teoria psicanalítica de grupo. São Paulo: Casa do Psicólogo.

Kaës, R. (2005). Os espaços psíquicos comuns e compartilhados. São Paulo: Casa do Psicólogo.

Kaës, R. (2010). Filiação e afiliação: alguns aspectos da reelaboração do romance familiar nas famílias adotivas, nos grupos e nas instituições. In: I. Trindade-Salavert (Org.), Os novos desafios da adoção (pp. 163-182). Rio de Janeiro: Companhia de Freud.

Kaës, R. (2011). Um singular plural: a psicanálise à prova do grupo (Luiz Paulo Rouanet, Trad.). Rio de Janeiro: Edições Loyola.

Krause, M. (2011). La psicoterapia: oficio sin ciência y ciencia sin oficio? Revista Colombiana de Psicologia, 20(1), 89-98.

Krause, M., De la Parra, G., Arístegui, R., Dagnino, P., Tomicic, A., Valdés, N., Vilches, O., Echávarri, O., BemDov, P., Reyes, L., Altimir, C., \& Ramírez, I. (2006). Indicadores genéricos de cambio en el proceso psicoterapéutico. Revista Latinoamericana de Psicología, 38(2), 299-325.

Magalhães, A. S., \& Féres-Carneiro, T. (2004). Transmissão psíquico-geracional na contemporaneidade. Psicologia em Revista, 10(16), 243-255.

Minayo, M. C. S. (2010). O desafio do conhecimento: pesquisa qualitativa em saúde. 12. ed. São Paulo: Hucitec.

Rosa, M. D. (2003). O não-dito como operador na clínica com crianças e adolescentes. In R. A. Pacheco Filho, M. D. Rosa, N. Coelho Junior, A. C. Lo Bianco, P. Endo, Carignato, T. T. (Orgs.), Novas contribuições metapsicológicas à clínica psicanalítica (pp. 97-113). Taubaté: Cabral.

Santos, M. A., \& Kawakami, E. A. (2003). Percursos do psicoterapeuta: da formação acadêmica ao exercício profissional. In R. A. Pacheco Filho, M. D. Rosa, N. Coelho Jr., A. C. Lo Bianco, P. Endo, \& T. T. Carignato (Orgs.), 
Novas contribuições metapsicológicas à clínica psicanalítica (pp. 229-246). Taubaté, SP: Cabral.

Souza, M. M., \& Teixeira, R. P. (2004). O que é ser um "bom" Aceito em 01/08/2014 psicoterapeuta? Aletheia, 20, 45-54.

Manoel Antônio dos Santos: psicólogo, livre-docente pela Universidade de São Paulo, mestre e doutor em Psicologia Clínica pelo Instituto de Psicologia da Universidade de São Paulo, professor associado 3 da Faculdade de Filosofia, Ciências e Letras de Ribeirão Preto, Departamento de Psicologia da Universidade de São Paulo, bolsista de produtividade em pesquisa do CNPq. 